\title{
Analysis of Socio-Demographic Characteristics as Risk Factors of HIV/AIDS in Rural Environment of Ivory Coast
}

\author{
Kouassi Joseph Tanoa, Qiuyun Suna, Ntumba Murphy Lavuaa, Zhefang Lia, Teya Kouame ${ }^{b}$
}

\begin{abstract}
AIDS is a public health problem of which, in spite of the authorized actions and efforts, the socio-economic, cultural, and political effects on humanity do not cease growing. Finding either preventive or curative solutions remains a big concern and the production of knowledge is still one of the alternatives. It is in this context that this study on the socio-demographic characteristics in connection with the evolution of the disease in rural environment was carried out. The concerned targets were the rural populations of Indenie-Djuablin, an area located at the East of the Ivory Coast. Thus, Affalikro, Aniassue, Amelekia, and Bettie, principal large villages of the chief town of Abengourou area were the sites of data collection of nearly 305 samples of individuals using a questionnaire and interview guides. The study used a quantitative and qualitative method with the dialectical and hypothetico-deductive approaches for the data analysis. The results obtained and discussed made it possible to conclude that the socio-demographic characteristics, while determining the attitudes and behaviors, expose the individuals to the HIV/AIDS contamination.
\end{abstract}

\section{Keywords}

Socio-demographic characteristics, risk factors, expansion, HIV/AIDS, rural environment

AIDS remains a crucial problem of development, which threatens the development of many countries in the world. Indeed, it even involves consequences on the health of the population. Also, it puts into questions the social relationships and appears of them. This fact as a crisis at the same time is individual disease and collective disease.

In Ivory Coast, research on the spread of the virus in connection with the risk factors in the rural area was certainly carried out, but deserved to be continued and enhanced. However, if the socio-demographic characteristics were explored, the majority of the studies were limited to the urban areas and were only subject to simple description without an in-depth study linking the factors to the spread of the disease.
The first interest of this study is to conduct an analysis linking the spread of AIDS with the risk factors herein considered as socio-demographic characteristics of the populations in the rural areas of Affalikro, Amelekia, Aniassue, and Bettie in order to direct the actions of fight for the improvement of the sanitary well-being of the populations.

This would consequently allow, the educators and

aHuazhong University of Science and Technology, China bUniversity of Felix Houphouet Boigny, Ivory Coast

\section{Correspondent Author:}

Kouassi Joseph Tano, Huazhong University of Science and Technology, 1037 Luoyu Rd, Hongshan, Wuhan, Hubei, China 
their peers, the parents, and all those who take part directly or indirectly in the fight against AIDS, as well as the organizations and committees fighting against this pandemic to understand and to better determine the sociological factors, which can constitute some obstacles to the behavioral change needed to cope with this disease. It is also a response from sociology to the problems caused by HIV/AIDS insofar as it could contribute to the redefinition of the policy of sensitization for the persuasion of the populations.

The second interest is that, in connection with the AIDS, it seems certain that the theoretical analysis of the strategic directions reaches its prevention target. However, very few studies carried out in sociology tried to determine the link between the spread of AIDS and its socio-demographic characteristics in the rural areas.

Thus, by analyzing this link through socio-cultural spaces of Affalikro, Amelekia, Aniassue, and Bettie, the study contributes to filling the gap, by detecting the underlying meaning, which requires the socio-demographic characteristics of the rural populations at the center of AIDS progression from the dialectical one like paradigm of approach of social reality.

The explanation of the spread of the AIDS vis-a-vis these socio-demographic characteristics as variables is crucially important in a way that it also makes it possible to highlight the limits of those through the risky attitudes and behaviors of the rural populations. Thus, the main aim of this study is to determine the link, which binds the socio-demographic characteristics of the populations to the spread of HIV/AIDS in the rural areas. In other words, the study aims at showing how the socio-demographic characteristics of the populations take part in the spread of HIV/AIDS in Affalikro, Amelekia, Aniassue, and Bettie.

Overall, the specific objectives presented as follows:
(1) To analyze the influence of sex, age, and matrimonial situation on the spread of HIV/AIDS in the rural areas;

(2) To explain the impact of the professional situation, religion, and educational level on the spread of HIV/aids in the rural areas;

(3) To show the contribution of the ethnicity in the spread of the AIDS in the rural areas.

By doing this, reaching these objectives certainly implies the identification of a methodology, which clearly defines the site, target, methods, techniques, and tools used as scientific bases of the study.

\section{METHODS}

The present study is descriptive and analytical. It took place in Indenie-Djuablin, an area located at the East of the Ivory Coast. It covers three departments, which are Abengourou (chief town of area), Agnibilekrou, and Bettie. It makes border with Ghana by the sub-prefectures of Niable in the department of Abengourou and Dame in the department of Agnibilekrou. The intended targets were people in the rural areas whose ages range between 15 and 49 years old. The qualitative method was used as the research basis.

In this research, the dialectical step was the mode of analysis of the data received from these targets. By the technique of quota and using the formula of Schwartz, the sample selected was of 305 people as divided by the whole localities chosen according to their rate of prevalence. These localities were Affalikro (6, 75\%), Bettie (6, 20\%), Amelekia (5, $49 \%$ ), and Aniassue (2, 78\%). Thus, the interview guides and the questionnaire were used to collect the data, which were eventually analyzed by using the SPSSS13.0 software.

However, the challenge faced during the study was the reluctance of certain women to answer the questions freely during the two days of the investigation. This urged the authors' initiative to 
meet their spouses with their agreement before having those women filled in the questionnaires. In addition, a documentary review also made it possible to collect the data, which were subject to a contents analysis. All this gave way to the results presented hereafter.

\section{RESULTS}

The socio-demographic characteristics studied here are a set of variables, which enable us to understand the attitudes and behaviors of the individuals. Those variables are sex, age, religion, educational level, marital status, professional situation, and ethnicity. They are determinants of facts about the individuals in a society.

\section{Sex, Age, and Matrimonial Situation}

In terms of sex, $54.4 \%$ men and $45.6 \%$ women were interviewed (see Figure 1). This rate of female respondents is explained by the fact why certain husbands refused to see their wives answer any questions, and that they had not obtained their authorizations. Indeed, for certain women, talking about sexuality without an agreement from their husbands is a sign of disobedience and even a lack of respect to them. Sometimes what causes divorces in certain homes is the acceptance of the following principle:

Once, people of NGO came to talk about condom to us. My husband was not here at that time, so I went to listen. On his arrival, he was told that I had been there for the talk. He was angry and he insulted me, and during one week, he did not speak to me. This is why, this time, I don't want to listen to you. But, I will answer your questions, but when he arrives explain to him the importance of this talk. (inhabitant of Bettie, 38 years old)

In addition to sex, the interviewed people were aged ranging between 10 and 75 years old and more. Among them, $77.8 \%$ have an age ranging between 10 and 44 years old. By observation, the surveyed population were mainly young people (see Figure 3).

In reference to marital status, $29.2 \%$ of the people surveyed were single and $31.1 \%$ were married. Moreover, $1.3 \%$ were divorced while $6.6 \%$ were widowed. Lastly, $31.8 \%$ live in cohabitation (see Figure 2).

\section{Pattern of the settlement surveyed according to the sex}

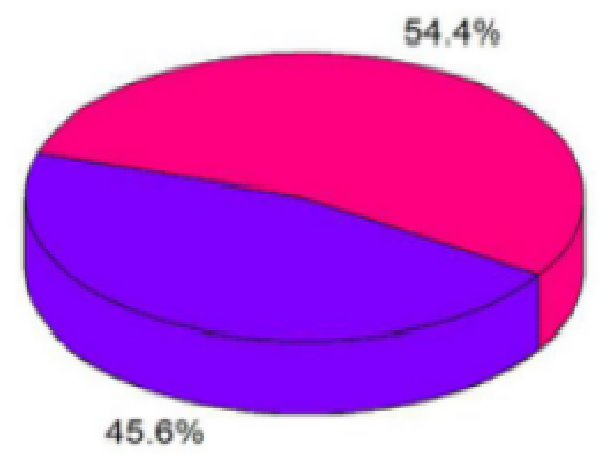

Figure 1. Pattern of the Settlement Surveyed According to Sex.

Note: Source: A survey on the socio-cultural practices and the spread of AIDS to the rural populations of the sub-prefectures of Affalikro, Aniassue, Amelekia, and Bettie in the area of Indenie-Djuablin (2016-2017). 


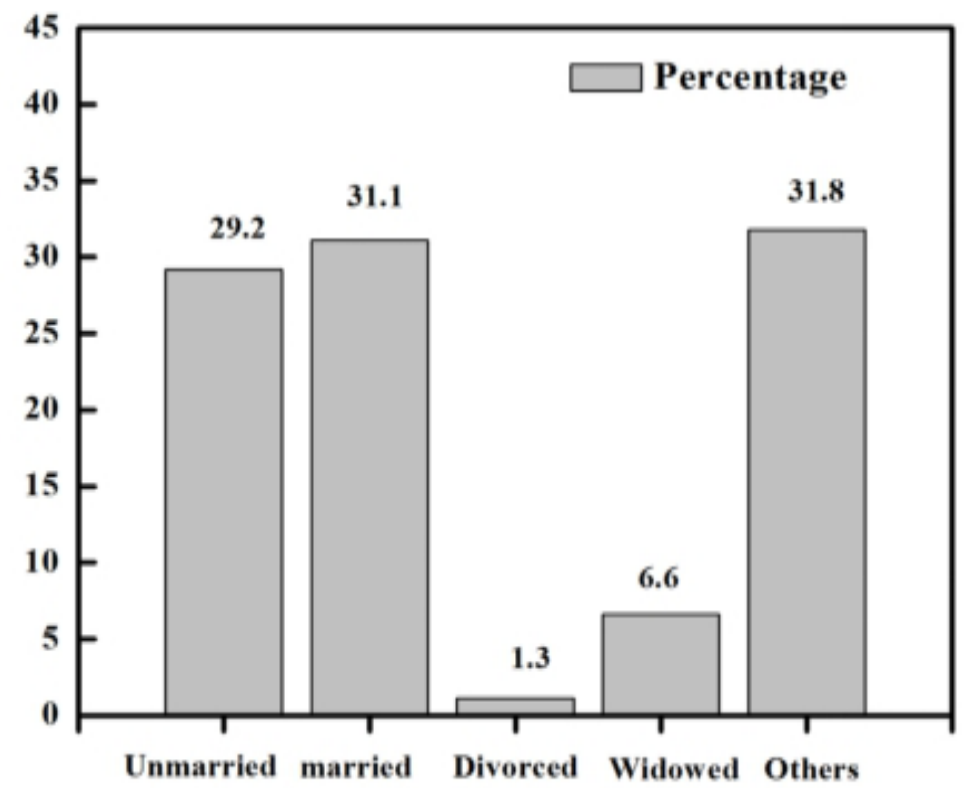

Figure 2. Distribution of Survey Samples Expressed as a Percentage by Marital Status.

Note: Source: A survey on the socio-cultural practices and the spread of AIDS to the rural populations of the sub-prefectures of Affalikro, Aniassue, Amelekia, and Bettie in the area of Indenie-Djuablin (2016-2017).

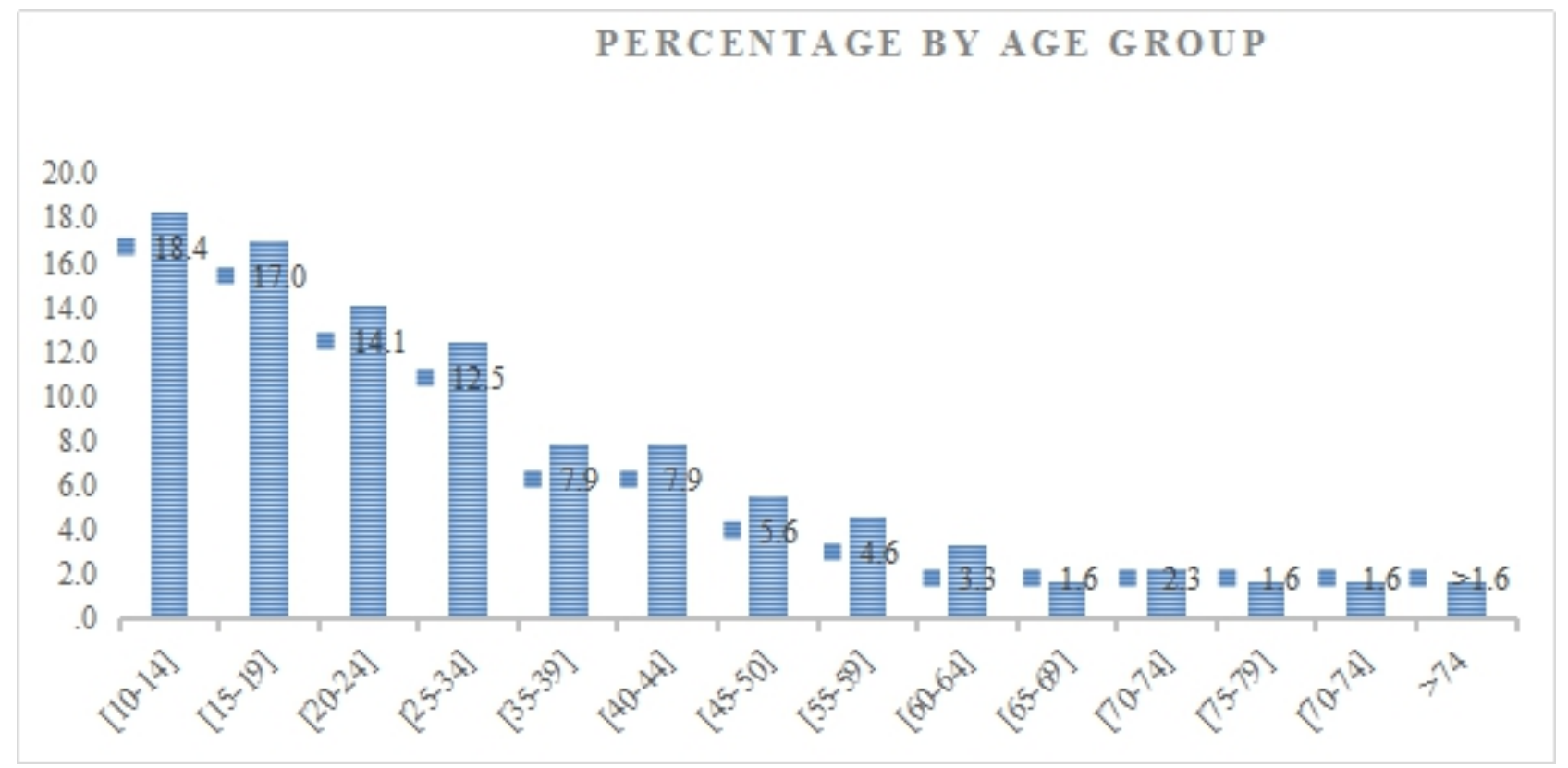

Figure 3. Distribution of Surveyed Samples Expressed as a Percentage by Age Group.

Note: Source: A survey on the socio-cultural practices and the spread of AIDS to the rural populations of the sub-prefectures of Affalikro, Aniassue, Amelekia, and Bettie in the area of Indenie-Djuablin (2016-2017). 


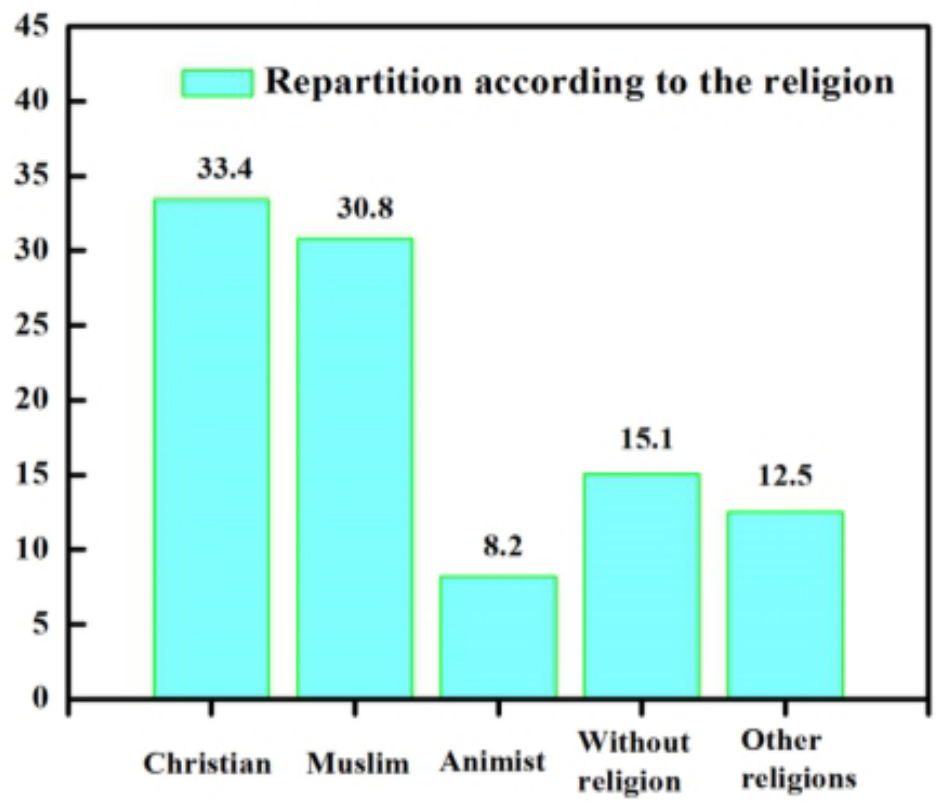

Figure 4. Distribution of Respondents According to Religion.

Note: Source: A survey on the socio-cultural practices and the spread of AIDS to the rural populations of the sub-prefectures of Affalikro, Aniassue, Amelekia, and Bettie in the area of Indenie-Djuablin (2016-2017).

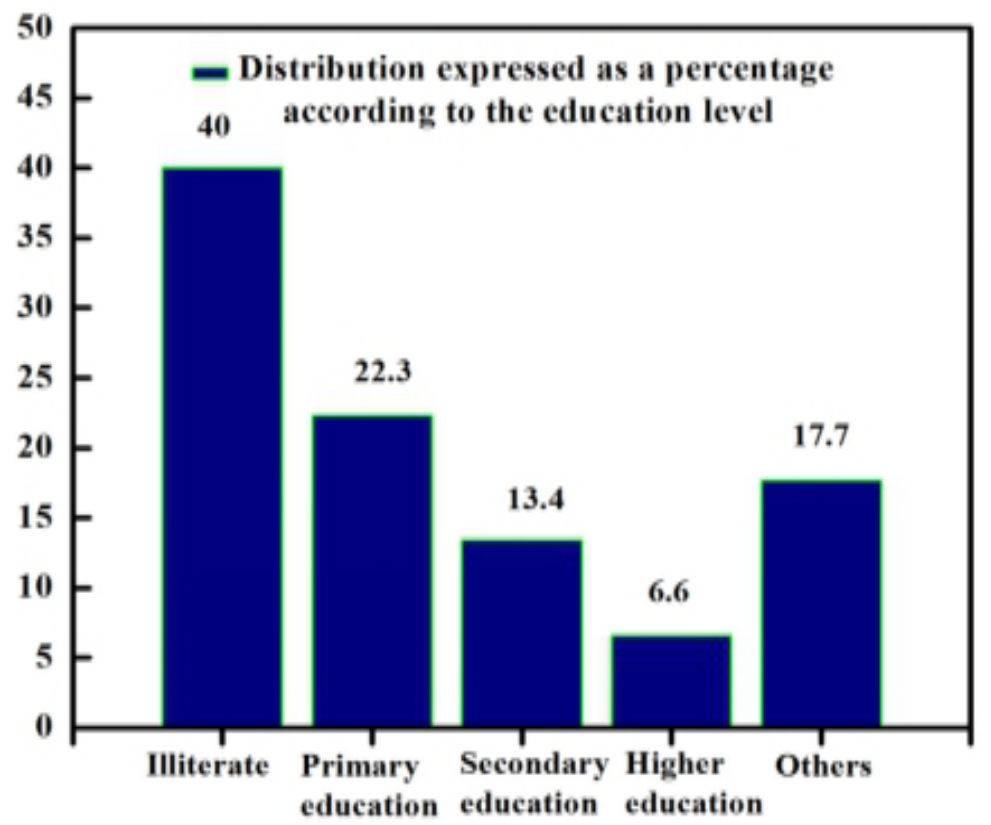

Figure 5. Distribution of Respondents According to Their Educational Level.

Note: Source: A survey on the socio-cultural practices and the spread of AIDS to the rural populations of the sub-prefectures of Affalikro, Aniassue, Amelekia, and Bettie in the area of Indenie-Djuablin (2016-2017). 


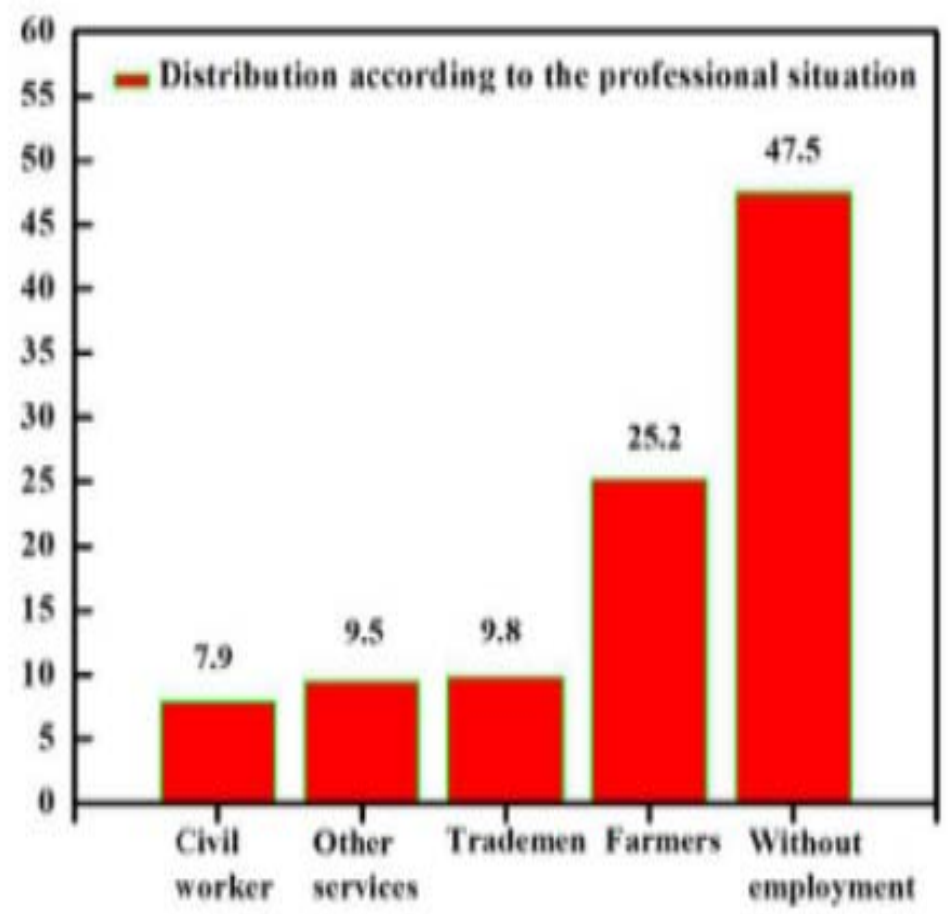

Figure 6. Distribution of Respondents According to the Socio-Professional Situation.

Note: Source: Survey on the socio-cultural practices and the spread of HIV/AIDS to the rural populations in the localities of Affalikro, Aniassue, Amelekia, and Bettie in the area of Indenie-Djuablin (2016-2017).

Table 1. Survey on the Socio-Cultural Practices and the Spread of HIV/AIDS to the Rural Populations

\begin{tabular}{|c|c|c|}
\hline Ethnos & Manpower Absolute value & Absolute value (\%) \\
\hline North Mande & 23 & 7.5 \\
\hline South Mande & 13 & 4.3 \\
\hline Krou & 26 & 8.5 \\
\hline Gur & 27 & 8.9 \\
\hline Akan & 99 & 32.5 \\
\hline Other Ivorian & 26 & 8.5 \\
\hline No Ivorian & 91 & 29.8 \\
\hline Total & 305 & 100 \\
\hline
\end{tabular}

Note: Source: Survey on the socio-cultural practices and the spread of HIV/AIDS to the rural populations in the localities of Affalikro, Aniassue, Amelekia, and Bettie in the area of Indenie-Djuablin (2016-2017).

All in all, the men were favorable to the investigation than the women. But, for the whole survey, the young people were the majority who live in cohabitation. Besides the variables presented above, the religion, the educational level, and their marital status were also studied.

\section{Religion, Educational Level, and Professional Situation}

It was noted that out of $64.2 \%$ of the people surveyed, 33.4\% were Christians and 30.8\% were Muslims (see Figure 4). It seemed that their faithfulness should be conducive to good practices since their sexual 
behaviors are supposed to be related to their religious education.

Furthermore, as regards educational level, $40 \%$ of the people surveyed were illiterate (see Figure 5).

In terms of socio-professional situation, 25.2\% were farmers and $47.5 \%$ were without employment (see Figure 6).

\section{Ethnicity}

The study reveals that $32.5 \%$ of survey respondents were Akan as a whole, in particular Agni, and 38\% were the other ethnicities. Also worth-noting were the $29.8 \%$ of respondents, who were not Ivorians (see Table 1).

On the basis of above given results, among the survey respondents, women were less willing to answer questions and, as a whole, they were young by majority and most of them lived in cohabitation. Also, the majority of them were religious, illiterate, and without employment. In terms of ethnicity, Akan, in particular the Agni, were the most numerous (32.5\%).

In light of these results, it is clear that, if the attitudes and behaviors of the individuals in the communities are influenced by these variables, the link to the spread of AIDS remains obvious and needs to be further discussed for a contribution to the epidemic evolution. It is presented in the rural localities of Indenie-Djuablin.

\section{DISCUSSION}

\section{Influence of Men on Women in Couple's Lives and Its Impact on the Spread of AIDS}

The analysis of the sex variable made it possible to discover that women refused to answer questions during the survey. For most cases, this is explained by the fear of the spouse, who would be annoyed if he did not give his agreement for a participation in the survey. In general, the male respondents did not give their agreement because they feared that their wives would consciously or unconsciously reveal the couple' secrets like what one of the husbands put it: "You know Sir, women talk too much without paying attention. They can say anything without thinking. Or rather, they talk just because they like talking” (married man of Affalikro, 45 years old).

This objection from husbands remains, on one hand, objective; but, on the other hand, consequential in the sense that this fact often deprives the wives of the necessary information on sexuality and AIDS, like it is shown by the following testimony: "Me, I've never known how to count a menstrual cycle, and I've never seen any condom with my naked eyes, which means that I need to know how to use it” (Amelekia's inhabitant, 34 years old).

\section{The Age Influence on the Use of the Condom by Young People}

The study reveals that $44 \%$ of the people surveyed are young and had their first sexual intercourse before the age of 15 . However, among them, only $17 \%$ were protected during their first sexual intercourse. Thus, many of them (27\%) run the risk of danger during their sexual intercourse. Accordingly, this sexual precocity in young people in rural area depends on their age as stated by one respondents: "You know, Sir, me I am 19 years old. When I am there, I often want to make love and once I see a beautiful girl, I want to court her" (inhabitant of Bettie, 19 years old).

\section{The Low Level of Education and Sexual Permissiveness in the Spread of AIDS in the Rural Areas}

The illiteracy (40\%) associated with the low educational level (22.3\%) of the individuals in the rural areas has a significant impact on the behavior of those rural residents. Indeed, there are many of those who can neither calculate their cycle (54\%) nor use a condom (52\%). This adds to the fact that there are those who think that AIDS is only transmitted by 
sexual intercourse (61\%) and those who believe that having AIDS is a fate (55\%). Thus, the knowledge the individuals have on AIDS and on the modes of transmission is not only incomplete but also erroneous. Therefore, this result of the study is in line with those of Zawada (2008) and of Djoko et al. (2011), which showed that if the individuals are somehow to know about the AIDS of nowadays, it is a common occurrence that their knowledge always remains inadequate and sometimes erroneous, especially regarding its modes of transmission.

In addition to that, sexual permissiveness is a practice, which puts the rural areas in danger. In fact, $56 \%$ of the people surveyed have sexual relations with several partners. In this respect, the situation constitutes a factor of propagation of the AIDS virus. The ideas put forward by John Caldwell and Pat Caldwell (1996) vindicate this finding when they affirm that in Africa, there is no constraint to the sexual relations with several partners for the simple reason that even married people keep their extra-marital affairs going.

\section{CONCLUSIONS}

The study of the socio-demographic characteristics in connection with the spread of VIH/AIDS was aimed to determine the direction of those in the evolution of the epidemic in the rural areas. These socio-demographic identities are defined in particular by sex, age, marital status, educational level, religion, socio-professional situation, and ethnicity. It appears that, with the dialectical step adopted for the analysis of information, these characteristics are presented in the form of true factors for risk and determinants which contribute, to a certain extent, to the spread of the virus in the rural communities in Ivory Coast. In summary, these factors are explanatory of the propagation of AIDS in the rural areas in the sense that, to the maximum extent, the individuals, especially the young people, remain vulnerable and exposed to HIV/AIDS contamination.

\section{References}

Abric, J. C. 1995. "Nature and Operation of the Core of a Social Representation: The Representation of the Company." International Books of Social Psychology 28:22-31.

Ainsworth, M., L. Fransen, and M. Over. 1997. “Confronting AIDS: Obviousness From the United Kingdom and AIDS Analysis Africa.” Pp. 12-40 in HIV/AIDS Country Profiles Ivory Coast.

Aka, K. R., A. Soucat, and E. Maville. 1997. "Current Costs and Theoretical Costs of the Assumption of Responsibility of the AIDS: Need for Rationalization of the Activities of Health Professional Trainings of Ivory Coast.” CHU of Treichville, PNLS. Xème CISMA, Abidjan.

Akoto, P. 1993. "Sociocultural Determinants of the Mortality of the Children in Black Africa, Assumptions and Search for Explanation.” Catholic Institute of Leuwen, Institutes of Development Academicia.

Atchen, G. and J. Andre. 1988. The Great Syndromes of the MST. Paris: ED. tech. EMC-Dermatology.

Balandier, G. 1971. Direction and Power: The Dynamic Social Ones. Paris: PUF.

Beani, J. C. 1995. "Sexually Transmitted Diseases Except AIDS.” Medical Corpus, p. 6.

Beat-Songue, P. 1998. "Influence of Social Environment on Sexuality and Reproductive Behaviors of the Teenagers in the South of Cameroun." In Sexuality and Reproductive Health During Adolescence in Africa: With Special Reference to Cameroon, edited by B. Kuate Defo. Boucherville: Ediconseil Inc.

Beaud, M. 2006. The Art of the Thesis. Paris: Éditions La Découverte.

Berestovoy, P. 2006. The Contribution of the Theory of the Social Representations to the Study of the Conflicts of Use in Environment. Retrieved July 16, 2010 (http://geirso. uqam.ca/iirso/Vol3Dec06/07BerestovovP.pdf).

Blanchet, A. 1985. History of the Nondirecting Maintenance of Research in Maintenance in Social Sciences: The Listening of the Word and the Direction. Paris: Dunod Editor.

Blankhart, D. 1997. "Evolution of the Problems of the Pregnant Young Women With Bangui.” UNICEF, Karthala Editions.

Bombereau, G. 2005. "Social Representations of the HIV-AIDS in Guadeloupe Recommendations for the Use of the Public Health. Fear or Death in the Heart in the French West Indies.” Laval University.

Bond, V. and P. Dover. 1997. "Men, Women and Disorder With Condoms: Problems Associated With Condom Uses 
by Migrating Workers in Rural Zambia.” Health Transition Review 7:377-391.

Bou-Assy, F. 2001. "Social Representations of the Endogamy and Its Biological Effects on the Health of the Descendants at Promised in Marriage Endgames: Case of Two Shiite Villages in the West of Baalbeck." Laval University.

Caldwell, J. C. and P. Caldwell. 1996. "The African AIDS Epidemic.” Scientific American 274(3):40-46.

Djoko, C. F., A. W. Rimoin, N. Vidal, U. Tamoufe, N. D. Wolfe, C. Butel, ... M. Peeters. 2011. "High HIV Type 1 Group $M$ pol Diversity and Low Rate of Antiretroviral Resistance Mutations Among the Uniformed Services in Kinshasa, Democratic Republic of the Congo." AIDS Research and Human Retroviruses 27(3):323-329.

Zawada, N. 2008. HIV/AIDS in South Africa. Retrieved (http://blogs.elon.edu/sasa/2008/11/18/hivaids-in-south-afri $\mathrm{ca} /)$.

\section{Bios}

Kouassi Joseph Tano, Ph.D. student, Faculty of Sociology, Huazhong University of Science and Technology, China; research field: cultural sociology.

Qiuyun Sun, Ph.D., professor, Faculty of Sociology, Huazhong University of Science and Technology, China; research field: cultural sociology.

Ntumba Murphy Lavua, Ph.D. student, School of Journalism and Communication, Huazhong University of Science and Technology, China; research fields: journalism and communication.

Zhefang Li, Ph.D., professor, School of Journalism and Communication, Huazhong University of Science and Technology, China; research fields: media effect, advertising and PR effect research.

Teya Kouame, Ph.D., Faculty of Sociology, University of Felix Houphouet Boigny, Cocody-Abidjan, Ivory Coast; research field: sociology of health rural. 